\title{
Determination of Trace Nd, Tb, and Ho in Environmental Samples by ICP-MS After Column Preconcentration and Separation With Titanium Dioxide Nanotubes
}

\author{
Shizhong Chen', Yuanyuan He, Dengbo Lu, and Xinle Guo \\ College of Chemical and Environmental Engineering \\ Wuhan Polytechnic University \\ Wuhan 430023, P.R. China
}

\section{INTRODUCTION}

Due to their special characteristics, rare earth elements (REEs) are widely used in different industrial and agricultural fields and thus inevitably discharged into the environment (1-3). Furthermore, they may enter the food chain from environmental media such as water, soil, and air. It was reported that long-term intake of low-dose REEs, even at very low concentration levels, may lead to their accumulation in the bone structure, cause changes in the bone tissue and aberration of bone marrow cells, and even bring about the generation of genetic toxicity in bone marrow cells $(4,5)$. Therefore, it is very important to develop a sensitive and reliable method for the determination of trace REEs in environmental samples.

Inductively coupled plasma mass spectrometry (ICP-MS) is one of the most effective tools used for the determination of trace REEs owing to its high sensitivity, low detection limits, wide linear dynamic range, and rapid multielement analysis capability. However, the direct determination of trace REEs in real samples by ICP-MS often suffers from the following problems: extremely low REE concentrations, complicated sample constituents, and remarkable matrix effects. In order to achieve reliable and accurate results, a chemical separation and preconcentration step is often required prior to their determina-

\footnotetext{
*Corresponding autbor.

E-mail: chensbizbong62@163.com
}

\begin{abstract}
A microcolumn preconcentration method coupled to inductively coupled plasma mass spectrometry (ICP-MS) was developed for the preconcentration and determination of trace rare earth elements (REEs) in environmental water samples, based on titanium dioxide nanotubes (TDNTs) as a solid phase extraction adsorbent. The experimental parameters for the preconcentration of REEs, such as $\mathrm{pH}$, sample flow rate and volume, eluent concentration and interfering ions on the preconcentration of REEs, were examined systematically.

Under the optimum conditions, the detection limits for $\mathrm{Nd}, \mathrm{Tb}$, and Ho were found to be $0.093,0.018$, and $0.025 \mathrm{pg} \mathrm{mL}^{-1}$, respectively, with a 100 -fold enrichment factor. The relative standard deviations (RSDs) were less than $4.6 \%(n=9$, $\mathrm{c}=1.0 \mathrm{ng} \mathrm{mL}^{-1}$ ). The proposed method was applied to the determination of trace rare earth elements ( $\mathrm{Nd}, \mathrm{Tb}$, and $\mathrm{Ho}$ ) in real samples with satisfactory results. The recoveries were between $93.5 \%$ and $104 \%$.
\end{abstract}

tion (6). A variety of methods, including solvent extraction, coprecipitation, ion exchange, solid phase extraction (SPE), chelating resin adsorption, and cloud point extraction have been commonly used for sample pretreatment (7-14).

Compared with traditional liquid-liquid extraction, SPE is one of the most effective preconcentration and separation methods and has aroused considerable interest because it reduces consumption and exposure to organic solvents, thus decreasing the amount of solvent for disposal. SPE is also less time-consuming than liquid-liquid extraction, and can provide more flexible working conditions and simple operation (15). The enrichment performance of SPE is related to the absorbents and the physical and chemical properties of target analytes. The adsorbent is crucial for achieving good selectivity and sensitivity. Thus, the development of a new adsorbent material with high selectivity and sensitivity is forever of interest to analysts.

In recent years, nanometer-size materials have drawn growing attention in analytical sciences because of their special properties, one of which is that most of the atoms of nanoparticles are on the surface. The surface atoms are unsaturated, possess high chemical activity, and can easily bind with other atoms. Consequently, interest in adapting nanometer materials as new adsorbents for the preconcentration and separation of substances has increased significantly. Some nanometer-size materials have been successfully used as solid-phase extractants for the preconcentration/separation of trace elements or impeding adsorption of organic compounds (16-22).

Titanium dioxide nanotubes (TDNTs), as an interesting member of nanomaterials, have been used for photodegradation as the photocatalyst. TDNTs should have much higher adsorption capacity than $\mathrm{TiO}_{2}$ nanoparticles because they have a large surface area, which 
makes them promising candidates as adsorbers $(23,24)$. However, to the best of our knowledge, studies on the application of TDNTs for the determination of trace REEs have received little attention so far. The main aim of this work was to develop TDNTs as a new adsorbent for the preconcentration and determination of trace REEs by ICP-MS. The adsorption characteristic of the analytes on TDNTs were investigated in detail. The proposed method was applied to the determination of trace $\mathrm{Nd}, \mathrm{Tb}$, and $\mathrm{Ho}$ in environmental samples with satisfactory results.

\section{EXPERIMENTAL}

\section{Instrumentation}

A Thermo Elemental X-7 ICP-MS (Thermo Elemental Corporation, USA), equipped with a standard low-volume glass impact bead spray chamber (Peltier-cooled to $+3{ }^{\circ} \mathrm{C}$ ), a concentric glass nebulizer and Fassel-type torch, was used in this work. The ICP-MS operating conditions and measurement parameters are listed in Table I. The ion lens settings, nebulizer flow rate, and torch position of the instrument were optimized daily in order to obtain the maximum ${ }^{115}$ In count rate. The samples and standards were spiked with $2.0 \mathrm{ng} \mathrm{mL}^{-1}$ of indium internal standard prior to determination.

The $\mathrm{pH}$ values of the solutions were controlled with a $\mathrm{pH}$ meter (Thermo Orion Corporation, USA), which is supplied with a combined electrode. A Model HL-2 peristaltic pump (Shanghai Qingpu Huxi Instrument Factory, P.R. China), coupled to a self-made polytetrafluoroethylene (PTFE) microcolumn (20 $\mathrm{mm} \times 3.0 \mathrm{~mm}$ i.d.), packed with TDNTs, was used for the preconcentration/separation process. A minimum length of PTFE tubing with an i.d. of $0.5 \mathrm{~mm}$ was used for all connections.

\section{Standard Solutions and Reagents}

The standard solutions of REEs (1.0 $\mathrm{mg} \mathrm{mL}^{-1}$ ) were prepared by diluting the stock standard solutions (obtained from the National Analysis Center of Iron \& Steel, Beijing, P.R. China). All reagents used were ultrapure or at least of analytical grade. High purity deionized water obtained from a Milli-Q ${ }^{\mathrm{TM}}$ A10 system (Millipore Corporation, USA) was used throughout this work. The $\mathrm{pH}$ of the solutions was adjusted by adding appropriate amounts of $\mathrm{HNO}_{3}$ or $\mathrm{NH}_{3} \cdot \mathrm{H}_{2} \mathrm{O}$.

\section{Column Preparation}

Sixty milligrams of TDNTs was introduced into a PTFE microcolumn (20 mm $\times 3.0 \mathrm{~mm}$ i.d.) plugged with a small portion of glass wool at both ends by a conventional method (25). Before use, a $1.0 \mathrm{~mol} \mathrm{~L}^{-1} \mathrm{HNO}_{3}$ solution and high purity deionized water were passed through the column in order to clean and condition it. Then, the column was conditioned to the desired $\mathrm{pH}$ value with $\mathrm{HNO}_{3}$ or $\mathrm{NH}_{3} \cdot \mathrm{H}_{2} \mathrm{O}$.

\section{Sample Pretreatment}

Water samples were collected from Wuhan (P.R. China) and stored in prewashed polyethylene bottles. Before analysis, the water samples were filtered through a cellulose membrane filter of $0.22 \mu \mathrm{m}$ pore size. The $\mathrm{pH}$ of the sample solution was adjusted to the desired value with $\mathrm{HNO}_{3}$ and $\mathrm{NH}_{3} \cdot \mathrm{H}_{2} \mathrm{O}$. Then, the procedure described above was applied to the samples.

A sample portion of $0.1000 \mathrm{~g}$ GBW 07603 Poplar Leaves (obtained from Perambulation Institute of Physical Geography and Geochemistry of the Geological and Mineral Ministry, Langfang, P.R. China) was accurately weighed into a $100-\mathrm{mL}$ Teflon ${ }^{\circledR}$ vessel, and then $4.0 \mathrm{~mL}$ of concentrated $\mathrm{HNO}_{3}$ and $2.0 \mathrm{~mL} \mathrm{H}_{2} \mathrm{O}_{2}$ were added, respectively. About 5 minutes after the first vigorous reaction had taken place, the digestion vessels were closed, placed into a microwave oven, and the samples digested at $180{ }^{\circ} \mathrm{C}$ (ramp, 10 minutes; hold, 15 minutes) at $1.0 \mathrm{~kW}$ power. After cooling, the solution was transferred into a Teflon beaker, $0.5 \mathrm{~mL} \mathrm{HClO}_{4}$ was added, and the solution heated to near dryness on a hot plate at $200{ }^{\circ} \mathrm{C}$. The residues were dissolved with $0.1 \mathrm{~mol} \mathrm{~L}^{-1}$ $\mathrm{HNO}_{3}$ solution and diluted to a desired volume. The blank was prepared in exactly the same way as the sample.

TABLE I

ICP-MS Operating Parameters

\begin{tabular}{ll} 
Plasma power & $1300 \mathrm{~W}$ \\
Plasma argon flow rate & $14.0 \mathrm{~L} \mathrm{~min}^{-1}$ \\
Auxiliary argon flow rate & $0.77 \mathrm{~L} \mathrm{~min}^{-1}$ \\
Nebulizer argon flow rate & $0.92 \mathrm{~L} \mathrm{~min}^{-1}$ \\
Sampler orifice (nickel) & $1.1 \mathrm{~mm}$ \\
Skimmer orifice (nickel) & $0.7 \mathrm{~mm}$ \\
Acquisition mode & Peak-jumping \\
Number of sweep & 100 \\
Dwell time & $10 \mathrm{~ms}$ \\
Acquisition time & $40 \mathrm{~s}$ \\
Number of measurements per peak & 3 \\
Isotopes & $146 \mathrm{Nd},{ }^{159} \mathrm{~Tb},{ }^{165} \mathrm{Ho}$, and ${ }^{115} \mathrm{In}$ \\
\hline
\end{tabular}




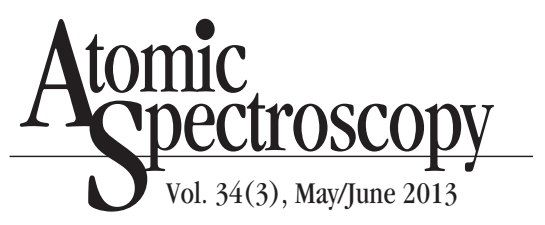

\section{Procedure}

In order to study the adsorption of REE ions on TDNTs under dynamic conditions, a portion of the aqueous sample solution containing REE ions was prepared and the $\mathrm{pH}$ adjusted to the desired value. The solution was passed through a column by using a peristaltic pump at the desired flow rate. Afterwards, the retained REE ions were eluted with $2.0 \mathrm{~mL}$ of $1.0 \mathrm{~mol} \mathrm{~L}^{-1} \mathrm{HNO}_{3}$ solution. The analytes in the effluents were determined by ICP-MS. The microcolumn could be used repeatedly after regeneration with $1.0 \mathrm{~mol} \mathrm{~L}^{-1} \mathrm{HNO}_{3}$ and deionized water. The recoveries of the analytes were calculated from the ratio of the concentration found by ICP-MS to that of the initial sample.

\section{RESULTS AND DISCUSSION}

\section{Effect of pH on Adsorption}

Due to its effects on the surface charge of the adsorbent and the speciation of the analytes, the sample $\mathrm{pH}$ value plays an important role in the SPE process. Thus, the retention of the REE ions on the column containing TDNTs was studied as a function of $\mathrm{pH}$. For this purpose, the $\mathrm{pH}$ values of the solutions were adjusted ranging from 1.0-9.0 with $\mathrm{HNO}_{3}$ and $\mathrm{NH}_{3} \cdot \mathrm{H}_{2} \mathrm{O}$ and then passed through the microcolumn. The retained ions were stripped off the microcolumn and measured by ICP-MS as described in the recommended procedure. It can be seen from Figure 1 that the adsorptions of the analytes were quantitative (>90.0\%) in the $\mathrm{pH}$ range from 7.0 to 9.0. Thus, a $\mathrm{pH}$ of 8.0 was selected for this work.

\section{Elution of Analytes}

Besides $\mathrm{pH}$, it was found that the eluent is also an important factor which affects the enrichment performance of SPE, because it determines whether or not the analytes are completely eluted from the adsorbent. From Figure 1 it can be seen that the adsorption of the REEs on the TDNTs was negligible at $\mathrm{pH}<1.0$. For this reason, various concentrations of $\mathrm{HNO}_{3}$ were studied for the desorption of the retained REE ions from the microcolumn. The experimental results indicated that $1.0 \mathrm{~mol} \mathrm{~L}^{-1} \mathrm{HNO}_{3}$ was sufficient for quantitative elution with good recoveries (>90\%).

In addition, the effect of eluent volume on the recovery of the analytes was investigated by keeping the $\mathrm{HNO}_{3}$ concentration of $1.0 \mathrm{~mol} \mathrm{~L}^{-1}$. It was found that quantitative recoveries ( $>90 \%$ ) were obtained with $2.0 \mathrm{~mL}$ of $1.0 \mathrm{~mol} \mathrm{~L}^{-1}$ $\mathrm{HNO}_{3}$. Hence, $2.0 \mathrm{~mL} \mathrm{HNO}_{3}$ was used as the eluent throughout the experiment.

\section{Selection of Sample Flow Rate}

The flow rate of the sample solution through the microcolumn affects the retention of the analytes on the adsorbent and the duration of the complete analysis. Therefore, the effect of the sample solution flow rate on the recovery of the analytes was investigated under the optimized conditions. A series of experiments ranging from $0.2-2.0 \mathrm{~mL} \mathrm{~min}{ }^{-1}$ were designed for obtaining the optimal flow rate by passing $20 \mathrm{~mL}$ of sample solution through the microcolumn with a peristaltic pump. It can be seen from Figure 2 that the retention of the analytes was practically unchanged up to $1.0 \mathrm{~mL} \mathrm{~min}^{-1}$, but decreased at higher flow rates due to a decrease in the adsorption kinetics. Accordingly, all subsequent experiments were performed at a flow rate of $1.0 \mathrm{~mL} \mathrm{~min}$.

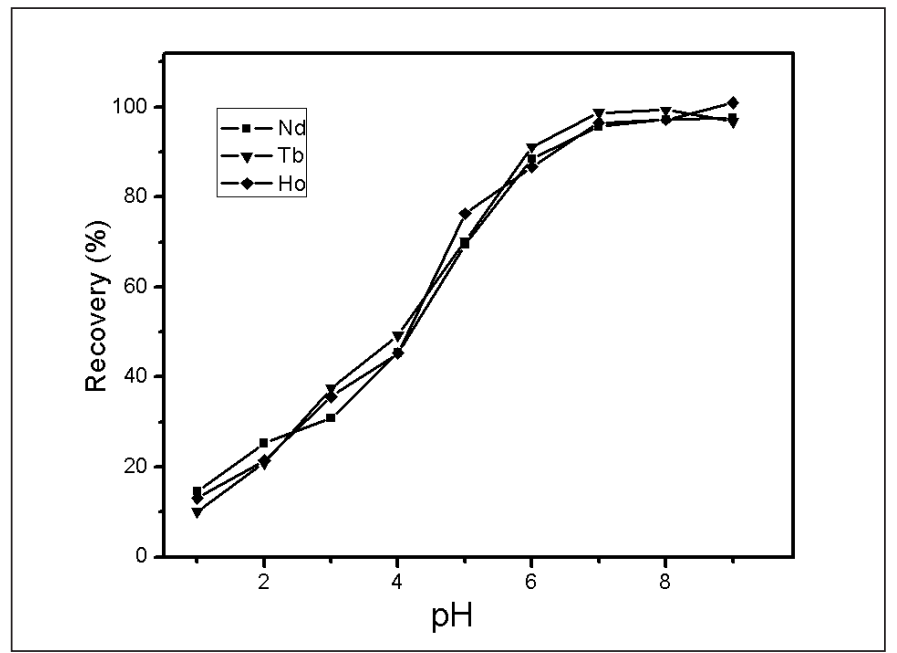

Fig. 1. Effect of $p H$ on recovery of REEs on TDNTs. REEs $\left(\mathrm{Nd}^{3+}, \mathrm{Tb}^{3+}, \mathrm{Ho}^{3+}\right): 2.0 \mathrm{ng} \mathrm{mL}^{-1}$; sample volume: $20 \mathrm{~mL}$.

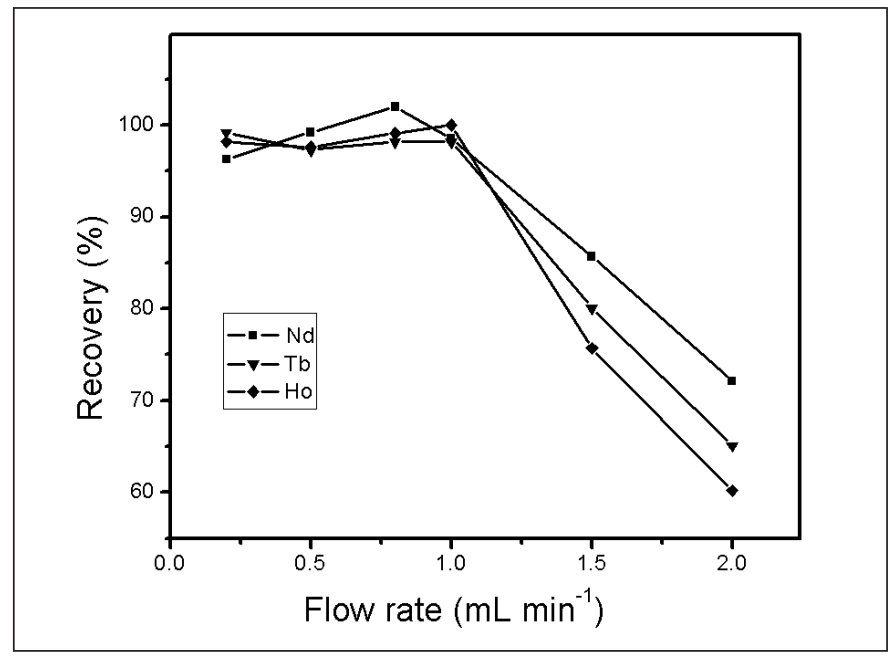

Fig. 2. Effect of flow rate on the recovery of REEs on TDNTs. $\mathrm{REEs}^{3+}\left(\mathrm{Nd}^{3+}, \mathrm{Tb}^{3+}, \mathrm{Ho}^{3+}\right): 2.0 \mathrm{ng} \mathrm{mL}^{-1}$; sample volume : $20 \mathrm{~mL}$. 


\section{Effect of Sample Solution Volume}

In order to obtain high preconcentration factors, the effect of sample volume on the adsorption behavior of the analytes on TDNTs was investigated by varying the sample volume containing $10 \mathrm{ng}$ of REE ions from 20 to $300 \mathrm{~mL}$. The results indicated that when the sample volume of the analytes was lower than $200 \mathrm{~mL}$, the recovery for all of the analytes was above $90 \%$ and remained constant, whereas a decrease of the recovery was observed with a continuous increase of sample volume. As described in the previous section, the analytes were quantitatively recovered using a $2.0-\mathrm{mL}$ volume of $1.0 \mathrm{~mol} \mathrm{~L}^{-1} \mathrm{HNO}_{3}$. An enrichment factor of 100-fold was obtained for the ions studied in this work. Considering the analysis time, a 20-mL sample solution was used for analyte preconcentration in the present work.

\section{Interferences of Diverse Ions}

The influences of possible matrix ions on the adsorption of the analytes were investigated. The tolerance limit of coexisting ions is defined as the largest amount making the recovery of the analyte less than $90 \%$. In these experiments, the interfering ion concentrations were varied, whereas the concentrations of the analytes were kept at $2.0 \mathrm{ng} \mathrm{mL}^{-1}$. The experimental results are presented in Table II.

TABLE II

Tolerance Limits of Coexisting Ions

\begin{tabular}{lc}
\hline Coexisting Ion & Mass Ratio \\
\hline $\mathrm{Na}^{+}, \mathrm{K}^{+}$ & $20,000^{\mathrm{b}}$ \\
$\mathrm{Ca}^{2+}, \mathrm{Mg}^{2+}$ & $10,000^{\mathrm{b}}$ \\
$\mathrm{Fe}^{3+}, \mathrm{Zn}^{2+}, \mathrm{Al}^{3+}$ & $500^{\mathrm{b}}$ \\
$\mathrm{SO}_{4}{ }^{2-}, \mathrm{SiO}_{3}{ }^{2-}$ & $2500^{\mathrm{b}}$ \\
$\mathrm{PO}_{4}{ }^{3-}$ & $2500^{\mathrm{b}}$
\end{tabular}

\footnotetext{
${ }^{a}$ Mass ratio: Foreign ion/REEs $\left(\mathrm{Nd}^{3+}, \mathrm{Tb}^{3+}, \mathrm{Ho}^{3+}\right)$.

${ }^{\mathrm{b}}$ Maximum amounts tested.
}

It can be seen that the major cations and anions were not found to interfere within the range of their amounts determined.

\section{Adsorption Capacity}

The adsorption capacity is an important parameter to evaluate the properties of the adsorbent since it determines how much adsorbent is required to quantitatively concentrate the analytes from a given sample solution. The adsorption capacity was investigated by the method recommended in the literature (26). 20-mL aliquots of a series of concentrations (5.0-30 $\mu \mathrm{g} \mathrm{mL}^{-1}$ ) were adjusted to the appropriate $\mathrm{pH}$, then preconcentrated and eluted. The amount of metal ions adsorbed at each concentration level was determined. Breakthrough curves were created by plotting the metal ion concentration versus the amount of metal ions adsorbed per gram of adsorbent (see Figure 3). The adsorption capacities obtained from the breakthrough curve were $11.7,13.2$, and $10.8 \mathrm{mg} \mathrm{g}^{-1}$ for $\mathrm{Nd}, \mathrm{Tb}$, and Ho, respectively.

\section{Detection Limits and Precision}

According to the definition of IUPAC, the detection limit (DL) is defined as the concentration corresponding to three times the standard deviation of the blanks. Under the optimum conditions, the detection limits for $\mathrm{Nd}, \mathrm{Tb}$ and Ho were found to be $0.093,0.018$, and $0.025 \mathrm{pg} \mathrm{mL}^{-1}$, respectively, with a 100-fold enrichment factor. The precisions for $\mathrm{Nd}, \mathrm{Tb}$, and $\mathrm{Ho}$, expressed as relative standard deviations (RSDs), were 2.7, 4.5, and $3.8 \%$, respectively $(\mathrm{n}=9$, $\mathrm{c}=1.0 \mathrm{ng} \mathrm{\textrm {mL } ^ { - 1 }}$ ).

\section{Sample Analysis}

The feasibility of the proposed method for REEs on TDNTs was explored by analyzing environmental water samples, including lake water and wastewater from an industrial site in Wuhan City. The reliability was checked by spiking the experiments. The results listed in Table III indicate that the recoveries are reasonable for trace analysis, ranging from $93.5-104 \%$. In order to establish the validity of the proposed method, the certified reference material GBW 07603 Poplar Leaves was analyzed by this procedure. The results as summarized in

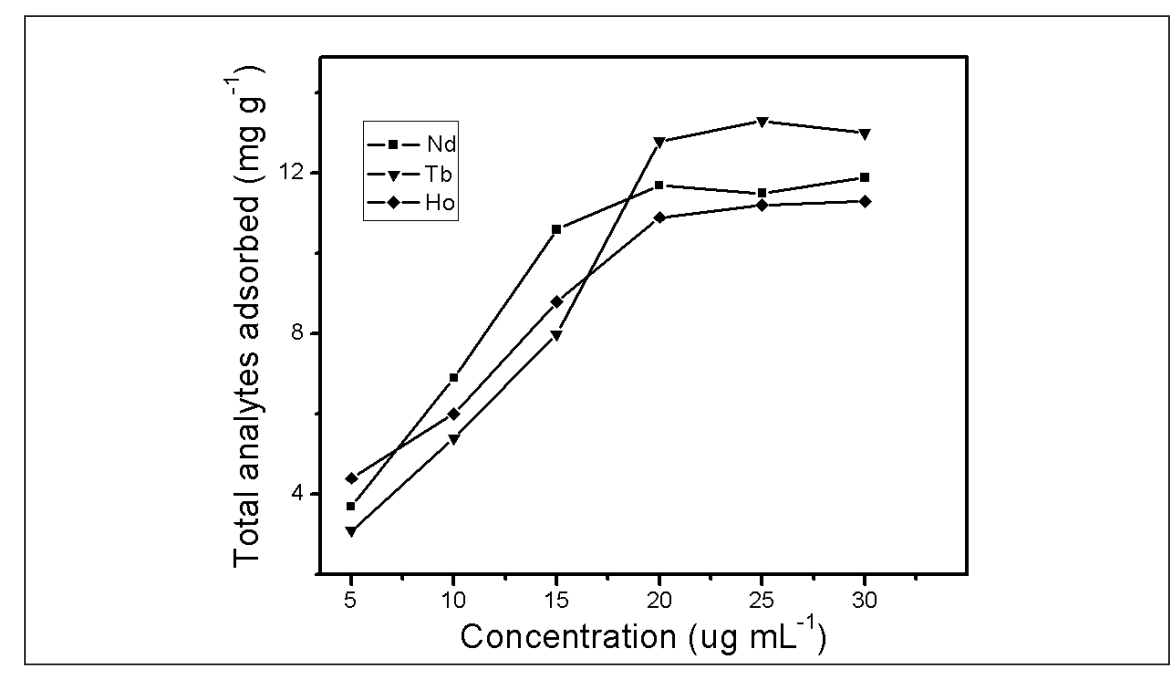

Fig. 3. Breakthrough curve of REEs on TDNTs. $p H=8.0$, sample volume $=20 \mathrm{~mL}$. 


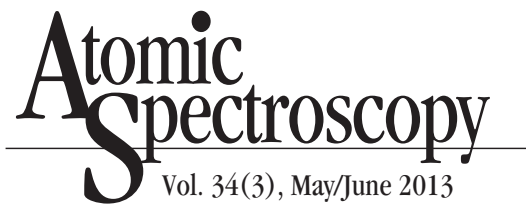

TABLE III

Analytical Results and Recoveries of REEs in Water Samples $(n=3)$

\begin{tabular}{lcccc}
\hline Sample & Element & $\begin{array}{c}\text { Added } \\
\left(\mathrm{ng} \mathrm{mL}^{-1}\right)\end{array}$ & $\begin{array}{c}\text { Found } \\
\left(\mathrm{ng} \mathrm{mL}^{-1}\right)\end{array}$ & $\begin{array}{c}\text { Recovery } \\
(\%)\end{array}$ \\
\hline $\begin{array}{l}\text { Dongxi Lake } \\
\text { Water }\end{array}$ & $\mathrm{Nd}$ & 0 & $3.14 \pm 0.15$ & - \\
& & 2.0 & $5.21 \pm 0.23$ & 104 \\
& $\mathrm{~Tb}$ & 0 & $0.056 \pm 0.006$ & - \\
& & 1.0 & $1.04 \pm 0.08$ & 98.4 \\
& $\mathrm{Ho}$ & 0 & $1.25 \pm 0.11$ & - \\
& & 2.0 & $3.12 \pm 0.23$ & 93.5 \\
Wastewater & $\mathrm{Nd}$ & 0 & $8.37 \pm 0.34$ & - \\
& & 5.0 & $13.4 \pm 0.49$ & 101 \\
& $\mathrm{~Tb}$ & 0 & $2.36 \pm 0.18$ & - \\
& & 2.0 & $4.29 \pm 0.23$ & 96.5 \\
& $\mathrm{Ho}$ & 0 & $3.12 \pm 0.15$ & - \\
& & 2.0 & $5.08 \pm 0.37$ & 98.0 \\
\hline
\end{tabular}

Table IV show that the determined values are in good agreement with the certified values for the analytes.

\section{CONCLUSION}

In conclusion, titanium dioxide nanotubes (TDNTs) as a novel solidphase extraction adsorbent packed in a microcolumn provide an effective preconcentration and separation procedure for the inductively coupled plasma mass spectrometry (ICP-MS) determination of trace rare earth elements (REEs) in environmental water samples. The adsorption behavior of the analytes on TDNTs was investigated systematically. It was found that the analytes can be retained on the TDNTs in the $\mathrm{pH}$ range of 7.0-9.0, desorbed quantitatively with $2.0 \mathrm{~mL}$ of $1.0 \mathrm{~mol} \mathrm{~L}^{-1} \mathrm{HNO}_{3}$, without any carryover in the next analysis. It may be expected that TDNTs have great potential as an adsorbent for the preconcentration and determination of trace/ultra-trace REEs in real samples.

\section{ACKNOWLEDGMENTS}

This work was supported by the Nature Science Foundation and the Education Department Foundation of Hubei Province, P.R. China.

Received February 18, 2013.

\section{REFERENCES}

1. E. Orvini, M. Speziali, A. Salvini, and C. Herborg, Microchem. J. 67(1-3), 97(2000).

2. S. Zhang and $X$. Shan, Environ. Poll. 112, 395 (2001).

3. A. Premadas, At. Spectrosc. 33(1), 14 (2012).

4. S. Hirano and K.T. Suzuki, Environ. Health Perspect. 104, 85 (1996).

5. Z.Y. Chen and X.Z. Zhu, J. Ecol. Rural Environ. 24, 88 (2008).

6. S. Martínez-Barrachina and M. del Valle, Microchem. J. 83 (1), 48 (2006).

7. D. Kara and M. Alkan, Microchem. J. 71(1), 29 (2002).

8. C. Frigge, and E. Jackwerth, Anal. Chim. Acta 242, 99 (1991).

9. P. Smichowski, L. Valiente, and A. Ledesma, At. Spectrosc. 23(3), 92 (2002).
TABLE IV

Analytical Results of REEs in SRM GBW 07603 Poplar Leaves

Found $^{\mathrm{a}}\left(\mu \mathrm{g} \mathrm{g}^{-1}\right) \quad$ Certified $\left(\mu \mathrm{g} \mathrm{g}^{-1}\right)$

$\begin{array}{ll}1.1 \pm 0.07 & 1.0 \pm 0.1\end{array}$

$0.031 \pm 0.003 \quad 0.025 \pm 0.002$

$0.028 \pm 0.002 \quad 0.033^{\mathrm{b}}$

${ }^{\text {a }}$ Mean value \pm standard deviation, $\mathrm{n}=3$.

10. G. Kaya, I. Akdeniz, and M. Yaman
At. Spectrosc. 29(4), 150 (2008).

11. Q. Jia, X. Kong, W. Zhou, and L. Bi, Microchem. J. 89 (1), 82 (2008).

12. P. Möller, P. Dulsky, and J. Luck, Spectrochim. Acta Part B 47, 1397 (1992).

13. A. Sanz-mendel, M. R. F. Campa, E. B. Gonzalez, and M. L. FernadezSanchez, Spectrochim. Acta Part B 54, 251 (1999).

14. J. L. Manzoori and A. Bavili-Tabrizi, Microchem. J. 72 (1), 1 (2002).

15. K. Pyrzynska, Crit. Rev. Anal. Chem. 29, 313 (1999).

16. J.G. Parsons, M.L. Lopez, J.R. Peralta-Videa, and J.L. Gardea-Torresdey, Microchem. J. 91(1), 100 (2009).

17. W. Yiwei, J. Yinyan, H. Deyan, W. Fang, and Z. Junxia, Microchim. Acta 159(3-4), 333 (2007).

18. S. Luther, N. Borgfeld, J. Kim, and J.G. Parsons, Microchem. J. 101, 30 (2012).

19. R. Yinzhe, F. Zhefeng, and W. Jianying, Microchim. Acta 158(3-4), 227 (2007).

20. W. Hong, W. Hongyu, H. Baoping, D. Baixiang, L. Jusheng, and T. Jiuying, Microchim. Acta 166(1-2), 41(2009).

21. Z. Li, S. Chen, D. Lu, and X. Cheng, At. Spectrosc. 30(6), 217 (2009).

22. Y. Cui, X. Chang, Y. Zhai, X. Zhu, H. Zheng, and N. Lian, Microchem. J. 83, 35 (2006).

23. Q. Zhou, X. Zhao, and J. Xiao, Talanta 77, 1774 (2009).

24. Q. Zhou, X. Zhao, and J. Xiao, At. Spectrosc. 29(4), 145 (2008).

25. S. Chen, L. Zhu, D. Lu, and X. Cheng, Microchim. Acta 169, 123 (2010).

26. A. Maqieira, H. A. M. Elmahadi, and R. Puchades, Anal. Chem. 66, 3632 (1994). 